\title{
THE DEVELOPMENT AND USE OF FARM LEVEL INDICATORS IN ENGLAND
}

\author{
Tzilivakis J. ${ }^{1}$, Findon R. ${ }^{2}$, Lewis K.A. ${ }^{3}$ \\ ${ }^{1}$ Senior Researcher, Agriculture \& Environment Research Unit, University of \\ Hertfordshire, UK \\ ${ }^{2}$ Head of Sustainable Agriculture Unit, Department for Environment, Food and Rural \\ Affairs, UK \\ ${ }^{3}$ Reader \& Head of Agriculture \& Environment Research Unit, University of \\ Hertfordshire, $U K$
}

Contact Person: Kathy Lewis. tel: +441707 284582, fax: + 441707 285258, e-mail:

K.A.Lewis@Herts.ac.uk

\begin{abstract}
In recent years the concept of 'sustainability indicators' has become important within agricultural policy development. Numerous indicators have been proposed by agricultural scientists and statisticians, which reflect the wide range of interests that are impacted by agriculture. It as been argued that such indicators provide a practical [and reasonable] means of understanding the concept of sustainability and measuring progress considering its multi-faceted nature. However, as policy tools, many indicators are highly technical in nature and often appear relevant only at national level (e.g. pesticides in groundwater, EU Producer Subsidy Estimate) and few have direct, close links with on-farm management decisions.

In order to drive progress towards sustainability it is important to define indicators at a level that is meaningful to the target audience and encapsulates the spatial and temporal diversity of the environment at a relevant level. It is also important that negative and positive trends can be linked to farm practices. Ready access to background information and advice will help farmers assess their performance, particularly if it allows them to benchmark against farmers in similar situations. This should also facilitate improvements.

In support of policy objectives the pilot national set of indicators of agricultural sustainability have been re-cast into indicators that can be collected, interpreted and compared at a farm level. The revised indicator set is directly linked to the national set via either disaggregation of the original data or by using a surrogate measure. A simple to use software package which prioritises the indicators according to farm type and which links trends with farm management decisions and practices identifying steps for improvements is being used as the main means of knowledge transfer.
\end{abstract}

\section{Introduction}

In recent years the concept of 'sustainability indicators' has become important within agricultural policy development. Such indicators have been derived in response to, amongst 
other issues, the understanding that sustainability can not be condensed into a single, simple definition or measurement.

The main principles are that specific resources and impacts are monitored and recorded to provide time series information that can then identify trends and so serve as an aid for decision making and policy development. Many indicators have been proposed by agricultural scientists, policy makers and statisticians considering the issues from different viewpoints. Most accept that the concept provides a practical and reasonable means of dealing with the multi-faceted nature of sustainablity ${ }^{1}$. A large amount of literature is currently in the public domain on sustainability indicators. These publications range from those addressing the use of a particular indicator as a measure of a specific aspect of agricultural sustainability (e.g. the work of Doran et $\mathrm{al}^{2}$, Arshad and Martin ${ }^{3}$ on soil quality or that on ecological indicators by Lefroy and $\left.\mathrm{Hobbs}^{4}\right)$. Others propose various concepts and frameworks for the classification of indicators ${ }^{5}$ and those which begin to develop and define sets of indicators to help assess how different policy measures affect environmental quality $^{6-10}$.

The UK Government published a pilot set of agricultural sustainability indicators ${ }^{10}$ in early 2000 to provide a means of measuring the economic, social and environmental impacts of agriculture in Great Britain. The principle purpose of these indicators is to provide direction for the development of agricultural and environmental policies at a national level. However, it was also hoped that farmers, landowners, non-governmental organisations and Local Agenda 21 groups would find the indicators valuable as a reference point for regional and local use. Consequently, there is a view that a wider role for the indicators should be developed and in particular there should be an acceptance and understanding of the indicators at the farm level and how management practices can influence the trends.

However, many of the indicators in the national set are highly technical in nature and are presented from the policy, top-down perspective. There is no breakdown of the indicator values by farm type or geographical demarcation, some are not measurable directly on farm and few have direct links with on-farm management decisions. As a consequence the importance of these indicators and the underpinning messages are lost at farm level. Any attempt to use this information to persuade farmers to take action is likely to fail but changes in farm management practice are needed before improvements at national level can be seen.

In order to address these issues a study was undertaken to re-cast the national set at farm level encapsulating the spatial and temporal diversity of farm environments. It was also seen as important to ensure that identified negative and positive trends were linked to farm practices. Appropriate advice should be provided to help individuals select indicators relevant to their situation, assess their performance and take steps for improvements where required. The revised farm-scale indicator set needed to be directly linked to the national set via either disaggregation of the original data or by using surrogate measures.

\section{Developing the Farm-level Indicators}

\subsection{Methods}


The national indicator set $^{10}$ describes 35 indicators for sustainable agriculture in Great Britain. They refer to primary agriculture and cover its impact on the rural economy, the use of inputs, resources, environmental quality and land use. These indicators have no subdivisions for geographical location or farm type. The study attempted to disaggregate the values for each of the 35 national indicators such that they became more meaningful at farm level.

The first step was to re-visit the original data used to calculate the national indicators to assess the feasibility of breaking these down in a statistically sound manner such that they become more meaningful regionally and / or by farm type. How this was achieved and the degree to which is was successful varied with each indicator. In some instances disaggregation was relatively simple as the national values had been derived in the first instance by the amalgamation of farm or regional data such as those derived from the UK's annual Agricultural Census ${ }^{11}$. In other cases the same Census statistics on the geographical distribution and extent of crop production and rearing of livestock was used to distribute nationally focused data in order to provide an indication on the regional and temporal changes in the indicator values. For other indicators completely new sources of data needed to be identified.

Some of the national indicators are not directly applicable to the farm level and those that do vary in their importance. However, the messages underpinning each is vital with respect to sustainable agriculture and so where relevancy was not high surrogate indicators were identified. The surrogates were chosen based on their relevancy, ability to convey the key messages, data quality and data availability. This approach was also used where, for a variety of reasons discussed later, it was not possible to work with the original data.

Another key objective of the project was to ensure knowledge transfer and so a simple-touse software tool for farmers has been developed which collates farm data in order to identify appropriate indicator values for a specific farm and location thereby providing a management focus. Indicator trends are associated with farm management decisions and practices. The indicator set is prioritised to enable farmers to identify the key areas where they needed to assess their farm performance and make improvements. This was done considering the farm type and management practices. This is linked back to the national level where feasible.

The project also included a significant amount of cooperation with the wider agricultural industry and various awareness raising activities to promote the concept and objectives of the pilot national and farm level indicators. This included workshops, seminars, posters and an audio-cassette explaining the background and purpose of the national and farm-level indicators.

\subsection{Data Issues}

The national indicators were initially calculated by a wide range of different organisations using a variety of different data types from detailed annual monitoring programmes to oneoff surveys that provided just "snap-shot" information. Trying to re-assemble and then recalculate the indicator values and their temporal trends proved difficult for a number of reasons. These included problems relating to: 
- Identification of techniques used and assumptions made in the original calculations: Where data arising from national monitoring programmes had been used the methods and procedures utilised for calculating the indicator values were relatively easy to identify. However, in some instances record keeping had been inadequate particularly concerning the exact calculation process and what assumptions had been made.

- Management of exceptionally large data-sets: In some cases the data sets were very large and required special software to be developed for the data handling and re-sorting before it was potentially useable, for example the Environment Agency pesticide monitoring database discussed in Case Study 1 of section 4.

- Management of small and incomplete data-sets: In some instances the indicators were calculated and extrapolated from poor quality or incomplete data-sets leaving trends open to interpretation.

- Statistical validity and interpretation: One of the concerns regarding the national indicators is that little information is available to the user regarding the statistical validity of the values and trends. This is equally important, if not more so, at finer scales and care needs to be taken to ensure that the indicator is not open to misinterpretation.

- Data ownership, copyright and intellectual property rights: Re-structuring within individual organisations and the wider industry, protection of individual and company interests and concern over the related costs were significant obstacles.

\subsection{The Farm Indicators}

Table 1 provides information on the identified farm-level indicators. Column 1 of the Table provides the national indicator number, title and the graphical data published for each. The second column summarises the type of data that was used in the original calculations (e.g. a basic survey or national census data). The method used to breakdown each of the national indicators is given in column 3. An explanation of the codes used can be found at the foot of the Table. The fourth column shows the farm level variations. For example, the first Indicator 'Assets and Liabilities' uses the temporal trends of the value of assets and liabilities in real terms to convey information on the economic status of UK agriculture. Within the farm level Indicator set greater detail is provided including data by farm type and tenure. Therefore, data viewed for an arable farm managed by an owneroccupier will be very different to that for a tenanted livestock farm. The final two columns provide information on any surrogate indicators included and any farm tools provided in the software package (section 3.1).

\section{A. The Rural Economy Indicators:}

A sustainable agriculture must be, by definition, economically viable. However, with the exception of 'assets and liabilities', the rural economy indicators do not have day-to-day relevance at farm level and are beyond easy control by the farmer. Whilst valuable at a policy level and for general interest, few have tenable links with specific farm practices. Most of these indicators had been calculated from farm Census data and so were statistically sound, had good historical trends and regional data was readily available.

\section{B. Farm Management Systems:}

Farm management systems take many different forms. They include those with narrow objectives such as the use of waste and water management plans to others which seek to manage the whole farm such as Integrated Farming Systems and organic farming; be they 
externally verified or self-assessed. These systems help individual businesses anticipate their potential environmental impacts and plan to minimise negative effects before undertaking practical farm management. The three national indicators categorised in this sub-set were found to be of general interest to farmers but the underpinning data was not of high quality and not sufficiently statistically reliable to break down to a farm level. The national indicators concerned with this issue were, therefore, supplemented by two surrogate measures. These were the number of pollution incidents attributable to agriculture and the number of wildlife poisoning incidents caused by pesticides. These data sets were chosen based upon the assumption that as awareness and implementation of environmentally sound farming practices increase pollution incidents should decrease. As both data sets are published annually and are in the public domain, the data is perceived to be of high quality, reliable and available

\section{Input Use and D. Resource Use:}

The type and quantities of farm inputs and the protection of natural resources will have a strong bearing on the sustainability of the farm. They will obviously have an influence on the local environmental quality and will also affect both the farm and regional rural economy. This issue is addressed by eighteen indicators covering input use (pesticides, nutrients and energy) and farm emissions. All of these were found to be of high relevance to the farm. However, the quality and reliability of the data was very variable, some being based on regular detailed surveys (e.g. the pesticide use surveys), whilst others were based on monitoring data (e.g. pesticides in groundwater) within a small area and extrapolation to other areas may not be sound. Others still were based on infrequent surveys (e.g. manure management). Regional disaggregation was possible in most cases. Some surrogate indicators were also identified. For example the OECD indicator of aquatic risk ${ }^{12}$ was included, as were regional average concentrations of nitrate and phosphate in surface waters.

\section{E. Conservation Value of Agricultural Land:}

Indicators related to the conservation value of agricultural land are used to reflect the aesthetic value of the countryside and its affect on biodiversity, as well as farmers' contribution to protecting the environment. Five indicators within the national set are concerned with these issues. Long-term historical data was not available for all the indicators however it was possible to identify more detailed data in some instances to provide an improved farm focus e.g. regional variations.

\section{Knowledge Transfer}

\subsection{The Software}

Software has been designed to provide a simple but visually interesting means of navigating and exploring both the national indicators and the re-cast farm level suite. Data is held in embedded databases and graphical displays are used to show the various spatial and temporal trends. Basic farm data (geographical location, farm type and tenure) is used to determine which disaggregated data is most appropriate for the user. There is also the option to supply more detailed information on the farm covering economic issues, input and resource use, management practices and conservation, which is subsequently used for calculating the more detailed farm level values of specific indicators. 
As the indicator set is quite large and the relevance of these, even at farm level, is variable (e.g. manure use will not be of high relevance to arable holdings not utilising it) methods of prioritising the indicators have been developed. Firstly, the full list is reduced to those indicators that are of direct relevance by farm type. Others are removed on the basis of supplied farm data. For example, if no irrigation takes place on the farm, the 'water use' indicator (Table 1: indicator 25) is not highly relevant to that farm. Then the farm values for a specific farm are used to highlight other indicators that may be of more relevance to the farm. For example, the trend in the ratio of assets to liabilities (Table 1: indicator 1) for the farm is examined and if the trend shows that it is decreasing this highlights the fact that this is a negative indication for the farm. Another example is heavy metals (Table 1: indicator 27). This indicator is highlighted as relevant if the typical heavy metal content of the soil on the farm is higher than the average for the county and/or above concentrations as laid out in the EC Directive on the Use of Sewage Sludge in Agriculture (86/278/EEC). This results in a smaller list of indicators, thus drawing attention to those indicators of most importance and relevance to the specific farm.

Other facilities within the software link identified negative and positive trends to farm practices and relevant, appropriate advice is provided to help individuals select indicators relevant to their situation, assess their performance and take relevant steps for improvements where required. Tools such as basic spreadsheets for estimating farm emissions and energy use have been included. Simple models are embedded for estimating risk to aquatic biodiversity from pesticides contaminating surface waters and risk to groundwater from pesticides leaching ${ }^{13}$. Farm values for the most relevant indicators can also be compared directly with national and / or regional values. Farm specific reports can be created and tailored to suit individual requirements.

\subsection{Other Technology Transfer Initiatives}

An audio-cassette has been produced which provides farmers and growers with general background information on the indicators and advises on their importance and interpretation linking this to management decisions. This has been freely distributed. The sound-files are also accessible via the software and via the Internet.

A website with a discussion forum was established early on in the study. This site included an electronic and interactive means of navigating the national indicator set (http://www.herts.ac.uk/aeru/indicators/).

\section{Case Studies}

The first case study has been selected to illustrate the regional variability of the data and its statistical validity. The following two scenarios are based on theoretical farms but based on actual holdings and real data. The focus of these has been chosen based on the prioritisation process within the software. The first is an arable farm considering farm inputs. The second is a livestock farm and looks at farm emissions.

All the examples given have been taken directly from the software. The latter two farm scenarios are amongst several available for exploration within the software itself. 


\subsection{Pesticides in surface waters}

Indicator number 13 of the national set is concerned with the amount of pesticides in rivers. The indicator is based upon Environmental Agency (EA) monitoring data and uses the proportion of river water samples that exceed the EC Drinking Water Directive (80/778/EEC) limit of $0.1 \mu \mathrm{g} /$ litre for both individual pesticides and the total retained. The exception being special cases where a more stringent limit of $0.03 \mu \mathrm{g} /$ litre has been introduced. The indicator graph shows the trend from 1992 onwards for six individual pesticides.

The EA database contains around 500,000 sample records for each year. Each sample recorded includes data on the chemical assayed, the site identifier, its grid reference, sample type (e.g. standard monitoring records, polluted site monitoring) and the analytical result.

The process utilised in order to extract information on a specific farm locality from this database involved spatially placing the farm in a hydrometric region (water catchment area) of the UK via the mapping of grid reference to hydrometric region. The records in the EA database relating to this region were identified excluding inappropriate records such as those from polluted sites. Using these records the percentage of samples found to exceed the EU pesticide limit within that hydrometric area were calculated.

As the database is very large and the intensity and purpose of sampling variable across the $\mathrm{UK}$, it was seen as prudent to carry out analysis of the sampling statistics in order to convey confidence to the user. This involved providing some indication of the number of sampling sites in relation to the catchment size and the number of samples taken per site. These two data items are then categorised into one of three bands 'high', 'medium' and 'low' and colour coded appropriately in order to give a visual and transparent indication of the sampling intensity both spatially within the catchment and at the actual sampling site. This overcomes the problem of the user being misled by the returned data. For example, if one sample had been taken in a very large catchment and it had been found to exceed the EU limit, the data would show $100 \%$ of samples failing that limit. Although true, this may be interpreted as a serious problem when in fact a low sampling intensity in a large catchment would demonstrate a poor level of data confidence. The following scenario can be used to illustrate this.

The Thames Basin is about 12,000 square $\mathrm{km}$ in area and provides water for around 12 million people including most of London. This region is monitored, on a regular basis, for a number of pesticides. In the following example data is given relating to monitoring samples assayed for the herbicide isoproturon. Figure 1 shows the sampling results. 


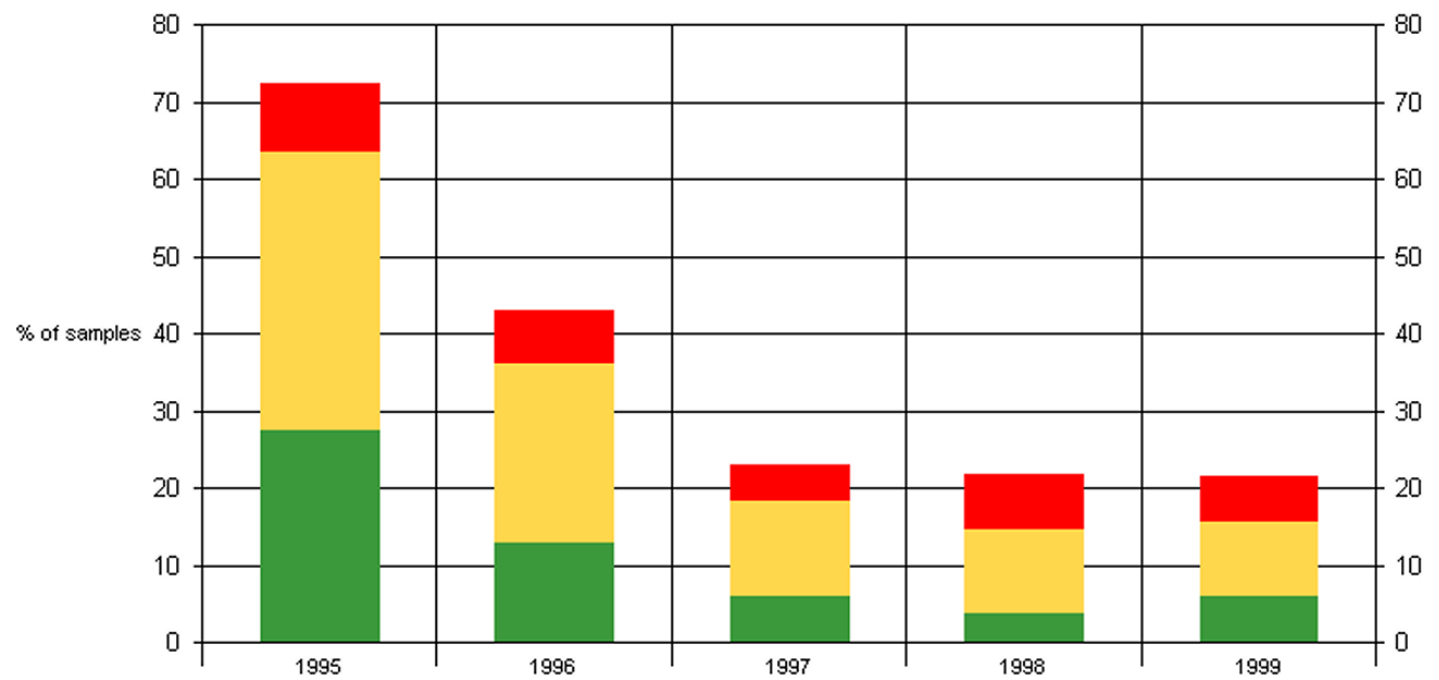

\section{Figure 1: Indicator 13: The Pesticide Isoproturon in the Thames Hydrometric Region}

Table 2 provides an example of the sampling data used to calculate the regional indicator values. Figure 2 shows the data for a different herbicide, atrazine, in the same catchment and illustrates how the situation can vary between pesticides, as this is dependant upon the local usage patterns and the ease at which the pesticide leaches.

Pesticide Monitoring Data - atrazine for catchment: 39

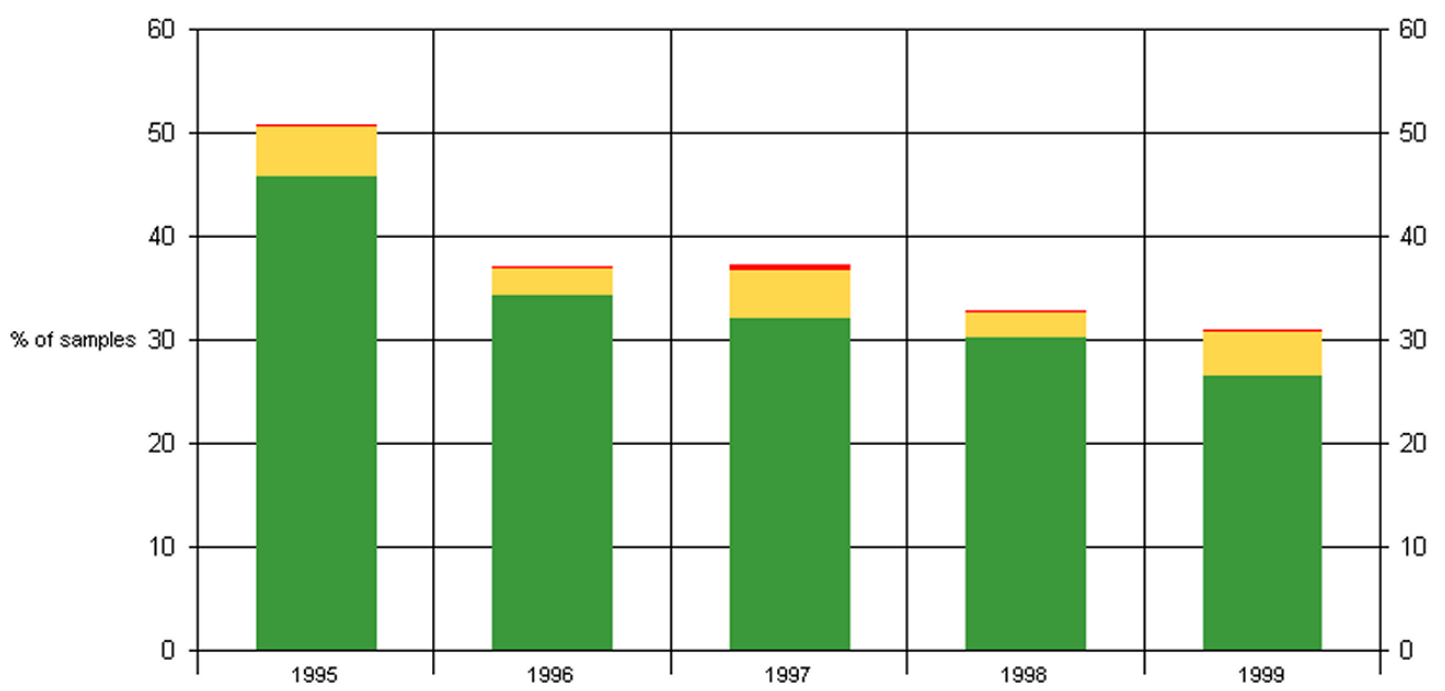

LOD to $<0.1 \mathrm{ug} / \mathrm{l} \quad 0.1$ to $0.5 \mathrm{ug} / \mathrm{l}$

$>0.5 \mathrm{ug} / 1$

Figure 2: Indicator 13: The Pesticide Atrazine in Rivers in the Thames Hydrometric Region 
For comparison and to illustrate the spatial variability data for the same pesticide but in a different hydrometric region (Exeter, Devon) is given in Figure 3.

Pesticide Monitoring Data - atrazine for catchment: 50

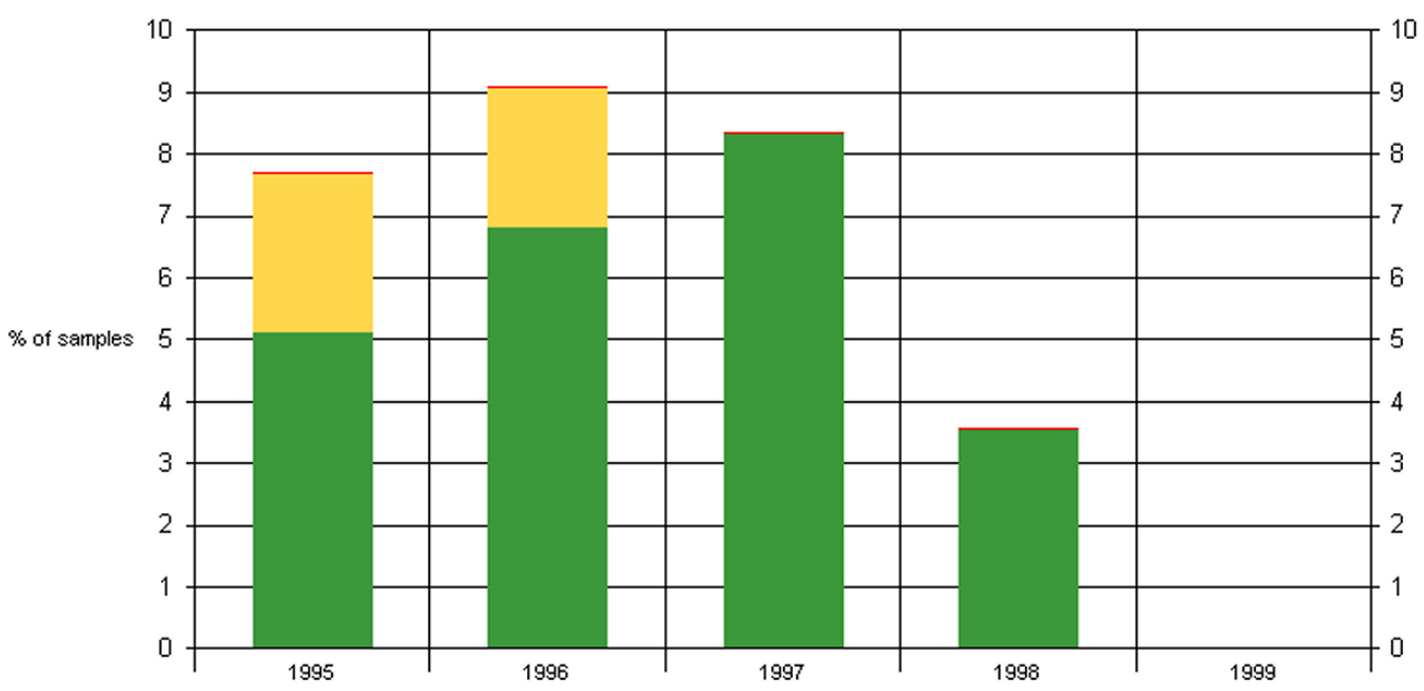

LOD to $<0.1 \mathrm{ug} / / \quad 0.1$ to $0.5 \mathrm{ug} / \mathrm{a} \quad \square>0.5 \mathrm{ug} / \mathrm{l}$

Figure 3: Indicator 13: The Pesticide Atrazine in Rivers in the Devon Region

This data alone does not provide any information on the amount of confidence that can be placed on the data. Table 3 provides the sampling statistics. The Spatial Intensity of the hydrometric region (catchment) is a description of the number of sampling sites in the region relative to the size of that region. The Sampling Intensity is a description of the intensity of the monitoring programme within that region calculated as a ratio of the number of samples taken divided by the number of sampling sites.

With respect to the Thames catchment a moderate amount of confidence can be placed on the data. However, with the Devon catchment both the spatial intensity and the sampling intensity are low, illustrating that data for this area is not so reliable.

\subsection{Pesticide Use on an Arable Farm Case Study}

Consider a 250 ha arable farm in Essex managed using the concepts and techniques of Integrated Crop Management. The farm's major crop is winter wheat but some oilseed rape and winter beans are also grown. Using the developed software it can be seen that the farm is likely to have a clay soil, rainfall is around $600 \mathrm{~mm}$ per year. For crop protection purposes the farm uses a range of pesticides including the insecticide cypermethrin, herbicides isoproturon and simazine, and the fungicides chlorothalonil and propiconazole.

The software can be used to explore whether these pesticides are causing a problem in the local catchment area, how much they are used (as quantities and area treated) and what the risk to aquatic biodiversity is. In this hydrometric region, of those pesticides being used on the farm only simazine and isoproturon are being detected in monitoring samples. No monitoring records for the other pesticides have been found. Graphs such as those shown 
in Figures 1 to 3 can be produced showing monitoring data. Figures 4 and 5 show that whilst both simazine and isoproturon are used on cereal crops, isoproturon is used in much greater quantities.

Quantity of simazine used on arable land

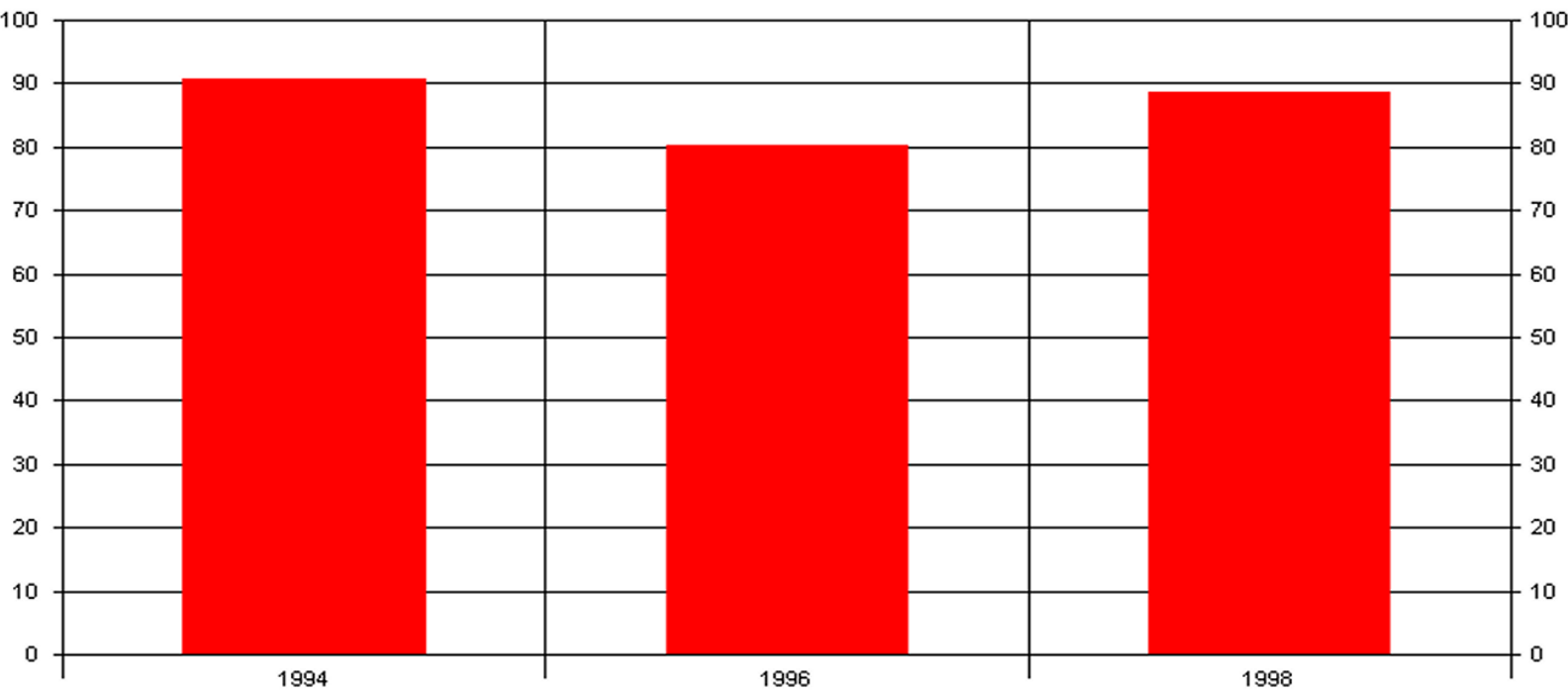

Figure 4: Indicator 15: Tonnes of Simazine used on Arable Land in England and Wales

Quantity of isoproturon used on arable land

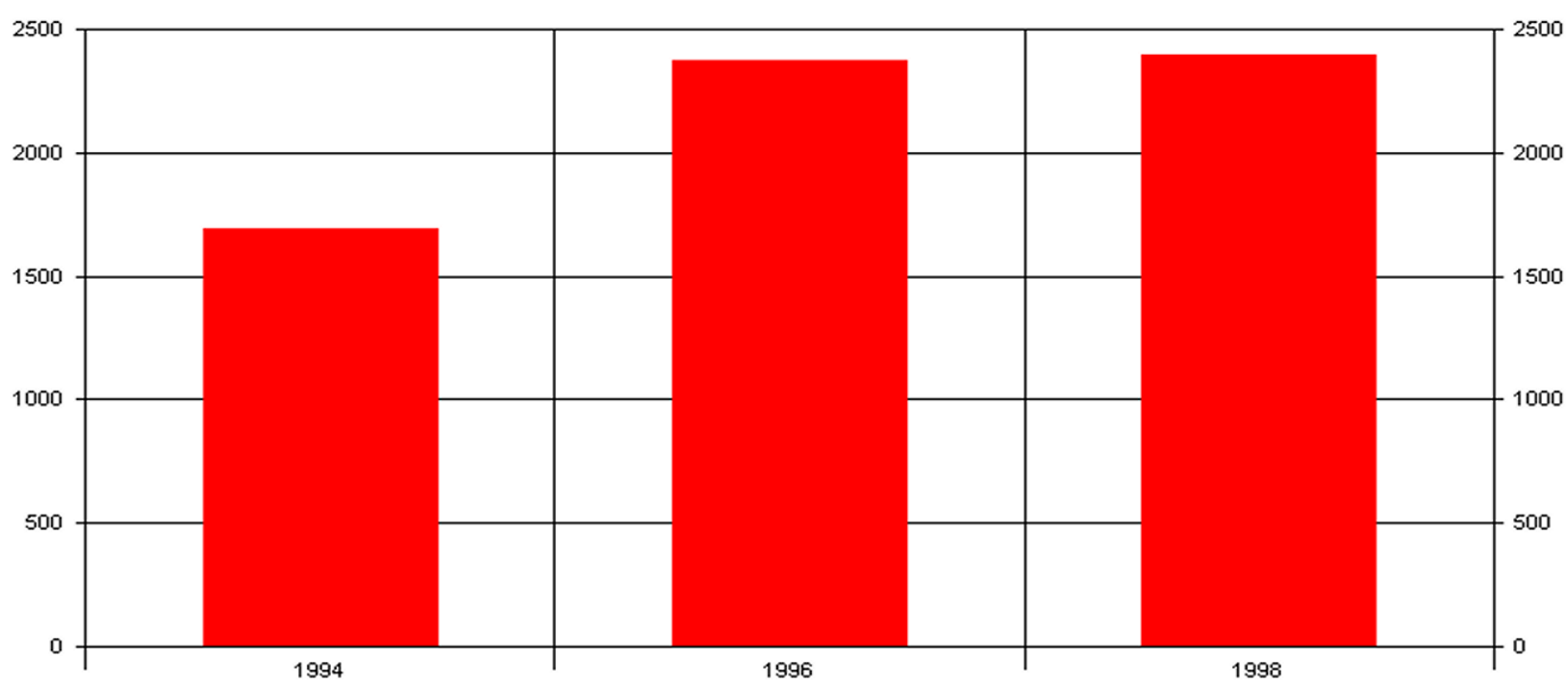

Figure 5: Indicator 15: Tonnes of Isoproturon used on Arable Land in England and Wales

The graphs displayed for indicator 16 show the temporal changes in spray area treated with pesticides and can be used to confirm usage patterns. The 'area sprayed' is calculated by multiplying the area treated by the number of sprays it receives. From these statistics around 0.09 million spray hectares receive simazine annually whilst 1.7 million spray hectares receive isoproturon. Using the software farm tools the risk from simazine to aquatic biodiversity can be explored. With an application rate of $3 \mathrm{~kg}$ active substance per 
hectare the risk is considered only acceptable if the spray area is not near surface water or where surface water is close by a 'no spray' zone is used to buffer the watercourse protecting it from spray drift. Simazine requires the implementation of a 'no spray' buffer zone as a statutory requirement of use. With respect to isoproturon considering an application rate of 1.0 litre of active substance per hectare the risk to aquatic biodiversity is considered acceptable with or without a 'no-spray' buffer. Whilst isoproturon is identified more frequently in the local surface waters and is used more widely on arable land the risk to aquatic biodiversity is greater from the use of simazine. Thus, the software helps focus the farmer's attention on the greater risks.

\subsection{Livestock Farm Case Study}

Consider a 200 ha livestock farm in Lancashire. The farm has dairy cows, sheep and pigs. Using the indicator software it can be seen that the farm is likely to have a loamy soil, rainfall is around $1100 \mathrm{~mm}$ per year. Using the prioritisation process in the software the indicators on manure management and emissions of ammonia and nitrous oxide are amongst those highlighted.

One of the principal causes of pollution arising from livestock farms is from the mismanagement of livestock manures and slurries. Using a surrogate measure linked to Indicator 20, which is concerned with manure management practices, the number of pollution incidents caused by organic manures within the North West region can be displayed. This plot is shown in Figure 6. Data shows that whilst incidents have declined sharply since 1994 they now appear to be relatively stable but are still of a concern.

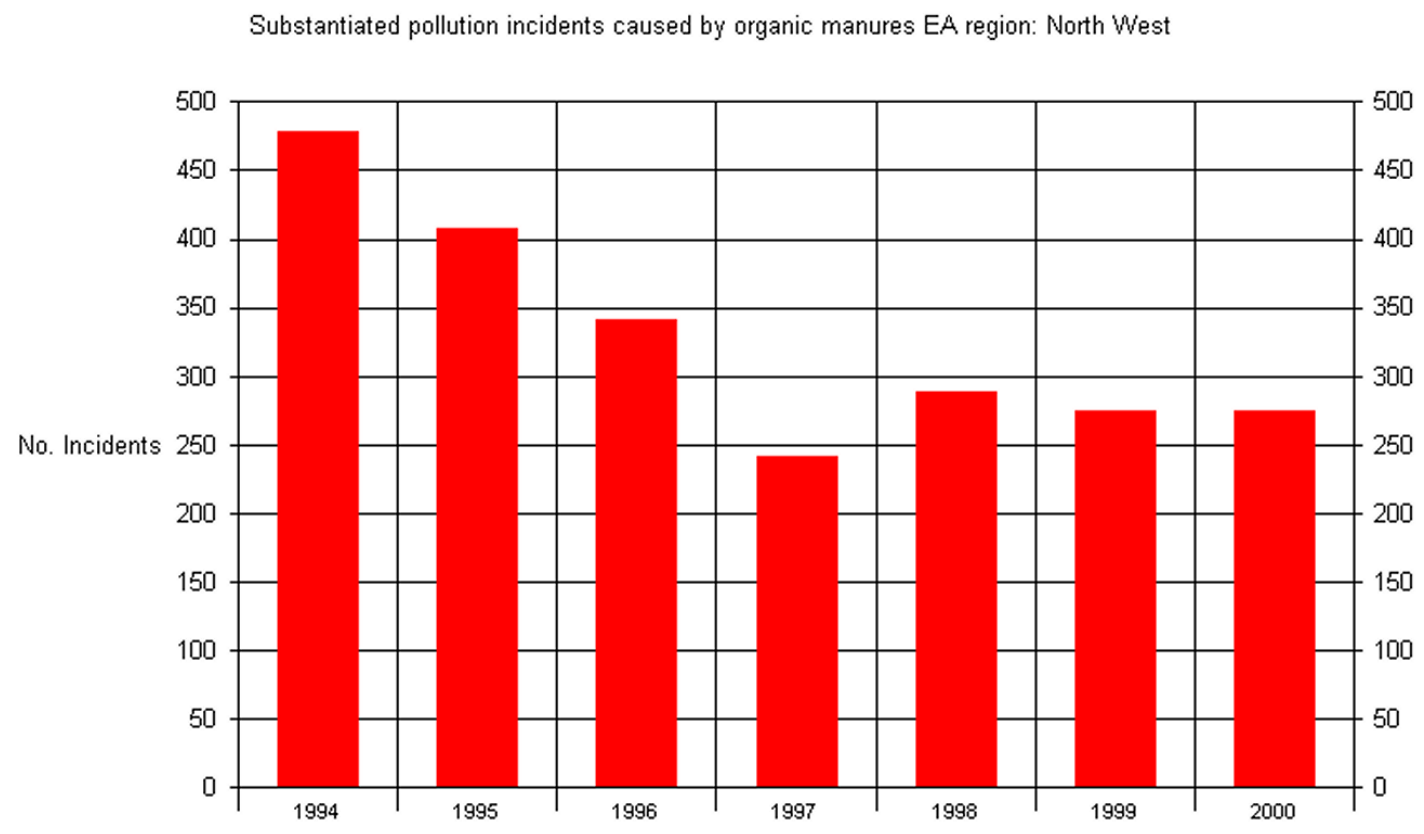

Figure 6: Data showing Pollution Incidents caused by Organic Manures in the NorthWest Region.

The software provides the user with information on best practice especially that concerned with providing adequate and sound storage provisions for manures and slurries. 
National Indicator 21 is concerned with emissions of ammonia. The best practice advice given on manure management also draws attention to ammonia emissions from livestock, raising awareness of this issue. To aid the farmer assess his own contribution towards the national figure the software estimates the emission levels based on the number of livestock. Figure 7 shows part of the report generated.

\begin{tabular}{|l|l|l|l|l|}
\hline Class & Head count & $\begin{array}{l}\text { Quantity applied } \\
\mathrm{kg} \mathrm{N}\end{array}$ & Emission factor & $\begin{array}{l}\text { Total NH3 emitted } \\
\text { as kg NH3 per yr }\end{array}$ \\
\cline { 2 - 4 } Cattle & 50 & $\mathrm{n} / \mathrm{a}$ & 9.6 & 617 \\
\hline Sheep & 300 & $\mathrm{n} / \mathrm{a}$ & 0.6 & 231 \\
\hline Lambs & 100 & $\mathrm{n} / \mathrm{a}$ & 0.1 & 13 \\
\hline Pigs & 50 & $\mathrm{n} / \mathrm{a}$ & 3.2 & 206 \\
\hline Poultry & 0 & $\mathrm{n} / \mathrm{a}$ & 254 & 0 \\
\hline Inorganic fertilisers & $\mathrm{n} / \mathrm{a}$ & 14000 & 0.016 & 288 \\
\hline TOTAL & $\mathrm{n} / \mathrm{a}$ & $\mathrm{n} / \mathrm{a}$ & $\mathrm{n} / \mathrm{a}$ & 1355 \\
\hline
\end{tabular}

\section{Figure 7: Indicator 21: Ammonia Emissions Report Calculated using a Tool within the Software.}

The software can also be used to display data showing modelling predictions of total nitrous oxide emissions in the county (Figure 8). For this case study data shows that the level of nitrous oxide, as N2O-N, from agriculture in the county of Lancashire falls into the 5.59 to $6.51 \mathrm{~kg} / \mathrm{ha}$ band which is considered to be high. Data for neighbouring counties are given for comparison and the farm contribution can also be calculated. Other surrogate measures show that livestock contribute around $20 \%$ to the total national N2O-N value.

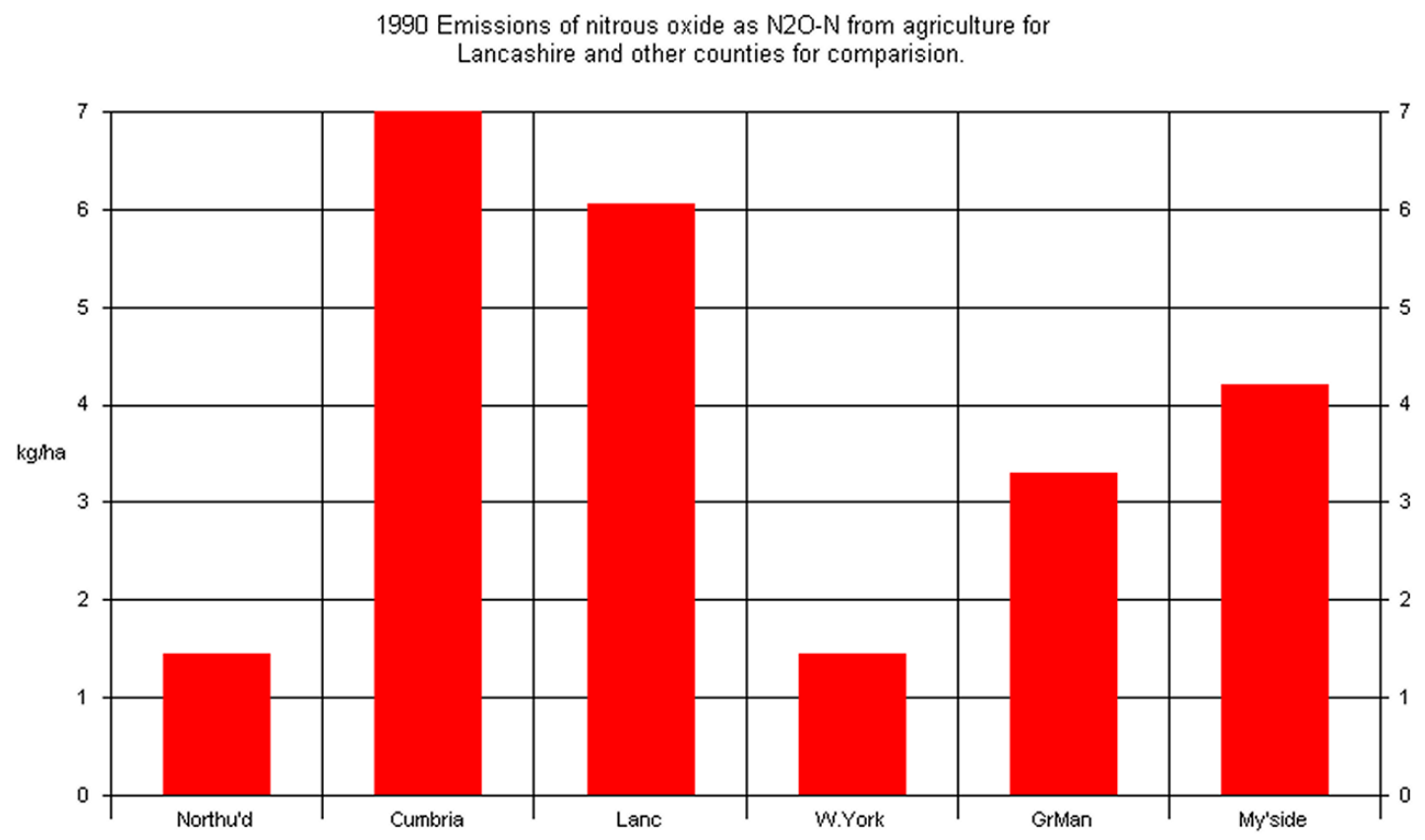

Figure 8: Indicator 22: Emissions of Nitrous Oxide by County. 
The farmer is therefore shown that livestock farms are key contributors to national ammonia emissions but whilst not the major cause of emissions of nitrous oxide they do make a contribution.

This case study illustrates how the information and presentation of the data is used to raise awareness of the indicators and how farm practices contribute towards the national picture.

\section{Conclusions}

In order to drive progress towards sustainability it is important to define indicators at a level that is meaningful to the target audience and encapsulates the spatial and temporal diversity of the environment at a relevant level. It is also important that negative and positive trends can be linked to farm practices. Ready access to background information and advice will help farmers assess their performance, particularly if it allows them to benchmark against farmers in similar situations. It should also facilitate improvements.

\section{Acknowledgement}

This project was funded by the UK Department for Environment, Food and Rural Affairs (DEFRA). The research was conducted in collaboration with LEAF (Linking Environment and Farming).

\section{References}

1 Pannell D.J., \& Schilizzi S. (1999) Sustainable agriculture: a question of ecology, equity, economic efficiency or expenditure? J. of Sustainable Agriculture, 13, 5766.

2 Doran J., Coleman J.D., Bezdicek D. \& Stewart B. (Eds) (1994) Defining soil quality for a sustainable environment. Soil Science Society of America.

3 Arshad M.A. \& Martin S. (2002) Identifying critical limits for soil quality indicators in agro-ecosystems. Agriculture, Ecosystems \& Environment, 88, 153160.

4 Lefroy T. \& Hobbs R. (1992) Ecological indicators for sustainable agriculture. Australian J Soil Water Conservation, 5, 22-27.

5 Organisation for Economic Cooperation \& Development (OECD) (1999) Environmental Indicators for Agriculture, Volume 1: Concepts and Framework, ISBN 9-264-17134 7.

6 Department of Environment, Transport and the Regions (1999) Quality of life Counts - indicators for a strategy for sustainable development for the United Kingdom: a baseline assessment, ISBN 1- 85112-343-1.

7 Environment Agency (2001) Identification and development of a set of national indicators for soil quality assessment. EA R\&D Project P5-053/02 Eds: PJ Loveland \& TRE Thompson.

8 Cowell S.J \& Parkinson S. (2002) Localisation of UK food production: an analysis using land area and energy as indicators, Agriculture, Ecosystems \& Environment, In press \& available online, 1947, 1-16. 
9 Organisation for Economic Cooperation \& Development (OECD) (1999) Environmental Indicators for Agriculture, Volume 2: Issues and Design, ISBN 9264-17041-3.

10 Ministry of Agriculture Fisheries and Food (2000) Towards Sustainable Agriculture: A Pilot Set of Indicators, DEFRA Publications PB4583.

11 Department of Environment, Food and Rural Affairs (2001) The June 2001 Agricultural Census, http://farmstats.defra.gov.uk/cs/aboutcensus.htm.

12 Hart A., Wilkinson D., Thomas M., \& Smith G. (2000) DETR Aquatic Risk Indicators: Report on Evaluation of Threshold and Profile Approaches.

13 Lewis K.A , Brown C.D., Hart A. \& Tzilivakis J. (2002) p-EMA: overview and evaluation of a software system designed to assess the environmental risk of agricultural pesticides, In press Agronomie. Due Jan 2003.

14 Lewis K.A. \& Tzilivakis J. (2000) The role of the EMA software on Integrated Crop Management and its commercial uptake, Pest Management Science Journal, 56, 969973. 
Table 1: The Farm-level Indicator Set

\begin{tabular}{|c|c|c|c|c|c|}
\hline $\begin{array}{l}\text { National Indicator [actual } \\
\text { data used] }\end{array}$ & Data type & $\begin{array}{l}\text { Breakdown } \\
\text { method }^{1}\end{array}$ & Farm Level breakdown & $\begin{array}{l}\text { Surrogate \& other } \\
\text { indictors }\end{array}$ & $\begin{array}{l}\text { Farm data used / } \\
\text { tools supplied }\end{array}$ \\
\hline \multicolumn{6}{|l|}{ Rural Economy: } \\
\hline $\begin{array}{l}\text { 1: Agricultural assets \& liabilities } \\
\text { [Value of assets over time] }\end{array}$ & $\begin{array}{l}\text { Annual survey } \\
\text { data }\end{array}$ & A & $\begin{array}{ll}- & \text { Country } \\
\text { - } & \text { Farm type } \\
\text { - } & \text { Tenure } \\
\end{array}$ & None & $\begin{array}{l}\text { Assets \& liability } \\
\text { calculations - farm data } \\
\text { compared }\end{array}$ \\
\hline $\begin{array}{l}\text { 2: Age of farmers [Proportion of } \\
\text { all farmers in } 3 \text { age brackets] }\end{array}$ & $\begin{array}{l}\text { Annual survey } \\
\text { data }\end{array}$ & $\mathrm{A}$ & $\begin{array}{ll}- & \text { Regional } \\
\text { - } & \text { Farm type } \\
\end{array}$ & None & None \\
\hline $\begin{array}{l}\text { 3: \% of tenanted holdings } \\
\text { [Proportion of area tenanted] }\end{array}$ & Census data & $\mathrm{A}$ & $\begin{array}{ll}\text { - } & \text { Regional } \\
\text { - } & \text { Farm type } \\
\text { - } & \text { Tenure }\end{array}$ & None & None \\
\hline $\begin{array}{l}\text { 4: EU Producer Support Estimate } \\
\text { [Proportion of net Producer } \\
\text { Support Estimate] }\end{array}$ & Annual EU data & B & - Commodity type & None & None \\
\hline $\begin{array}{l}\text { 5: Payments for agri-environment } \\
\text { activities [\% Expenditure] }\end{array}$ & $\begin{array}{l}\text { Government } \\
\text { Statistics }\end{array}$ & A & - Scheme type & None & None \\
\hline $\begin{array}{l}\text { 6: Income from farming } \\
\text { [Total income over time] }\end{array}$ & Census data & $\mathrm{A}$ & \begin{tabular}{|ll} 
- & Country \\
- & Farm type \\
- & Farm size \\
- & Tenure \\
\end{tabular} & Off-farm income & None \\
\hline $\begin{array}{l}\text { 7: Average earnings [Earnings } \\
\text { over time] }\end{array}$ & $\begin{array}{l}\text { Annual Survey } \\
\text { data }\end{array}$ & $\mathrm{A}$ & $\begin{array}{l}\text { - } \begin{array}{l}\text { Worker type e.g. full-time, } \\
\text { part-time, casual }\end{array} \\
\end{array}$ & $\begin{array}{l}\text { Detailed snapshot for } \\
2000\end{array}$ & None \\
\hline $\begin{array}{l}\text { 8: Agricultural productivity } \\
\text { [Productivity index over time] }\end{array}$ & $\begin{array}{l}\text { Government } \\
\text { Statistics }\end{array}$ & B & $\begin{array}{ll}- & \text { Input type e.g. fertilisers } \\
\text { - } & \text { Labour type } \\
\text { - } & \text { Output type e.g. Crop } \\
\end{array}$ & None & None \\
\hline $\begin{array}{l}\text { 9: Agricultural employment } \\
\text { [Persons employed] }\end{array}$ & Census data & B & $\begin{array}{ll}\text { - } & \text { Worker type } \\
\text { - } & \text { Regional }\end{array}$ & EC Statistics & None \\
\hline
\end{tabular}




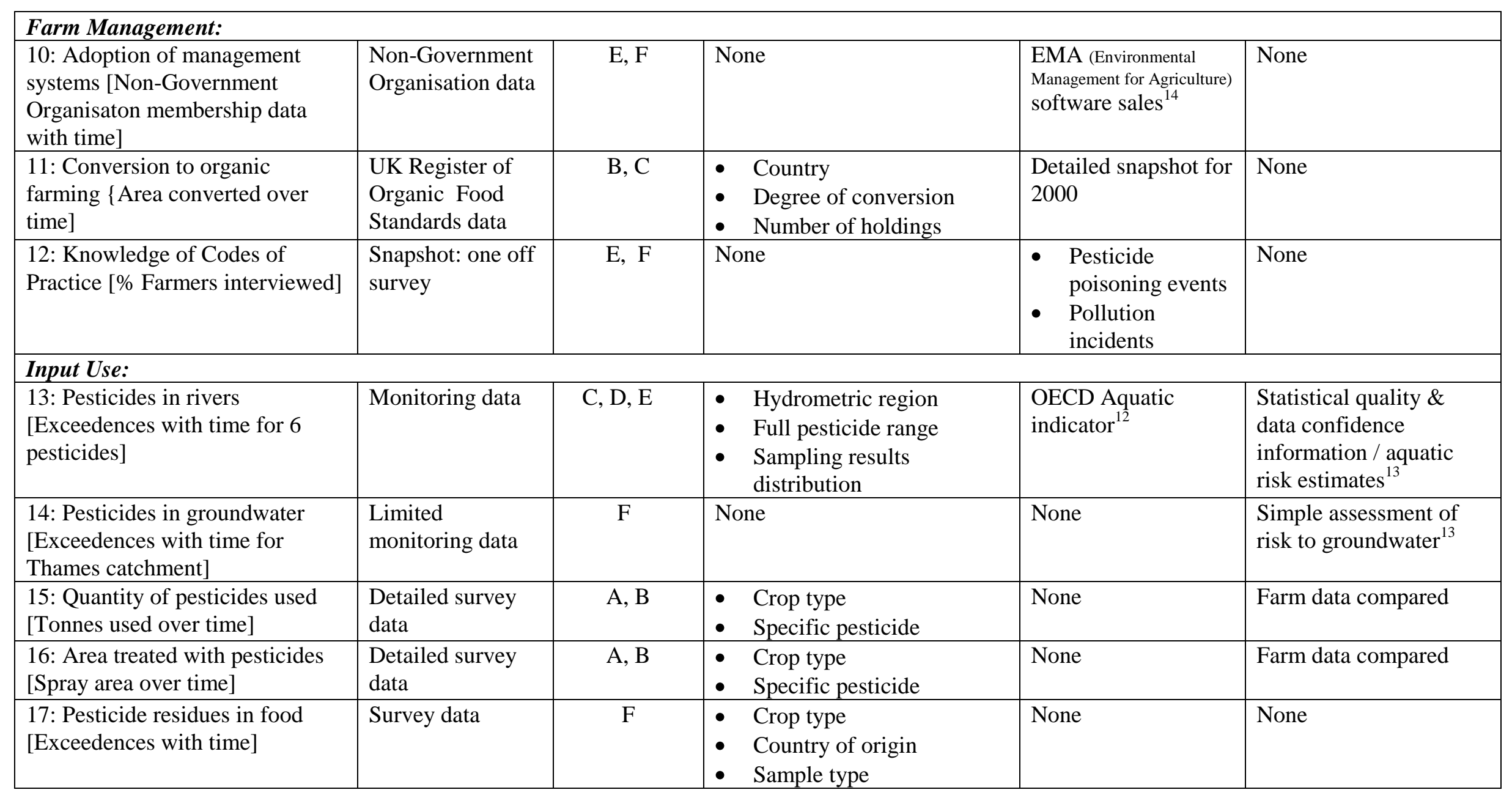




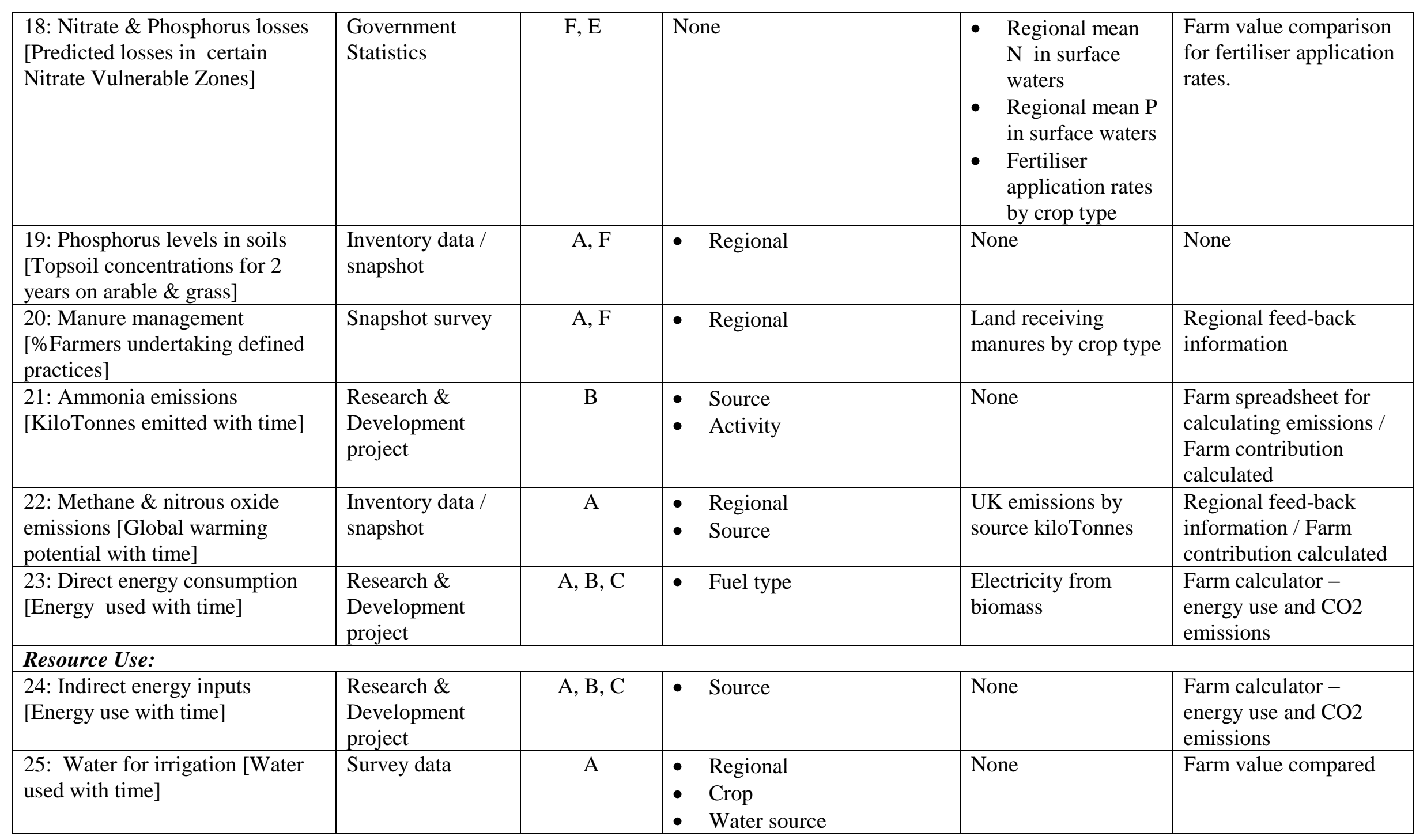




\begin{tabular}{|c|c|c|c|c|c|}
\hline $\begin{array}{l}\text { 26: Organic matter content of soil } \\
\text { [\% Samples falling into } 3 \\
\text { concentration brackets] }\end{array}$ & Inventory data & $\mathrm{A}$ & - Regional & None & $\begin{array}{l}\text { Statistical information/ } \\
\text { farm value compared }\end{array}$ \\
\hline $\begin{array}{l}\text { 27: Heavy metals in topsoil } \\
\text { [Concentration by heavy metal } \\
\text { for two sample years] }\end{array}$ & Inventory data & $\mathrm{A}$ & - $\quad$ Regional snapshot & None & Farm value compared \\
\hline $\begin{array}{l}\text { 28: Area of agricultural land } \\
\text { [Area in use with time] }\end{array}$ & Census data & $\mathrm{A}, \mathrm{C}$ & $\begin{array}{ll}\text { - } & \text { Land use } \\
\text { - } & \text { Cropping area by region } \\
\text { - } & \text { Livestock numbers } \\
\end{array}$ & None & None \\
\hline $\begin{array}{l}\text { 29: Change in land use [Area lost } \\
\text { with time] }\end{array}$ & $\begin{array}{l}\text { Government } \\
\text { Statistics }\end{array}$ & $\mathrm{A}$ & - Regional & $\begin{array}{l}\text { Previous use } \\
\text { information }\end{array}$ & None \\
\hline $\begin{array}{l}\text { 30: Planting of non-food crops } \\
\text { [Area planted with time] }\end{array}$ & Census data & $\mathrm{A}$ & - Regional & $\begin{array}{l}\text { Detailed snapshot } \\
2000\end{array}$ & None \\
\hline \multicolumn{6}{|l|}{ Conservation Value: } \\
\hline $\begin{array}{l}\text { 31: Land committed to } \\
\text { conservation [Area committed } \\
\text { with time] }\end{array}$ & Survey data & A & $\begin{array}{ll}\text { - } & \text { Regional } \\
\text { - } & \text { No agreements or area } \\
& \text { committed by scheme } \\
\end{array}$ & None & Farm value compared \\
\hline $\begin{array}{l}\text { 32: Features [Length of feature } \\
\text { by feature type] }\end{array}$ & Survey data & $\mathrm{A}, \mathrm{B}, \mathrm{C}$ & - Regional & None & $\begin{array}{l}\text { Farm data compared / } \\
\text { variation of units used }\end{array}$ \\
\hline $\begin{array}{l}\text { 33: Area of cereal margins under } \\
\text { environmental management } \\
\text { [Margin area with time] }\end{array}$ & $\begin{array}{l}\text { Government } \\
\text { Snapshot } \\
\text { Statistics } \\
\end{array}$ & A, B & - Regional & None & Farm value compared \\
\hline $\begin{array}{l}\text { 34: Area of semi-natural } \\
\text { grassland [Area or species } \\
\text { number with time] }\end{array}$ & $\begin{array}{l}\text { Government } \\
\text { Snapshot } \\
\text { Statistics }\end{array}$ & A, B & $\begin{array}{ll}\text { - } & \text { Regional } \\
\text { - } & \text { Area type } \\
\text { - } & \text { Grass type }\end{array}$ & None & Farm value compared \\
\hline $\begin{array}{l}\text { 35: Populations of farm birds } \\
\text { [Population index with time] }\end{array}$ & $\begin{array}{l}\text { Non-Government } \\
\text { survey data }\end{array}$ & $\mathrm{A}, \mathrm{B}$ & - Regional & Other bird groups & None \\
\hline
\end{tabular}

Notes:

1 Disaggregation methods: A - Original data used directly as this had been amalgamated to formulate national value; B - New source of data identified; C - National value distributed by national statistic; D - National indicator supplemented by additional data; E - Surrogate indicator or measure identified; F - No further breakdown possible due to either poor data quality or no available data. 
Table 2: An Example of Regional Sampling data (Thames Catchment for Isoproturon)

\begin{tabular}{|l|l|l|l|l|l|}
\hline & $\mathbf{1 9 9 5}$ & $\mathbf{1 9 9 6}$ & $\mathbf{1 9 9 7}$ & $\mathbf{1 9 9 8}$ & $\mathbf{1 9 9 9}$ \\
\hline $\begin{array}{l}\text { Number of Samples LOD } \\
\text { pesticide / ml }\end{array}$ & 119 & 81 & 30 & 19 & 34 \\
\hline Number of Samples 1-5 ug pesticide / ml & 155 & 141 & 60 & 49 & 52 \\
\hline Number of Samples >5 ug pesticide / ml & 37 & 42 & 22 & 32 & 30 \\
\hline Total number of samples & 430 & 612 & 486 & 457 & 537 \\
\hline Number of sample sites & 20 & 25 & 23 & 28 & 26 \\
\hline
\end{tabular}

Note:

1: $\mathrm{LOD}=$ Limit of Detection

Table 3: Conveying Statistical Confidence

\begin{tabular}{|c|c|c|c|c|c|}
\hline Isoproturon in catchment 39 & 1995 & 1996 & 1997 & 1998 & 1999 \\
\hline Spatial Intensity $^{1}$ & Low & Medium & Medium & Medium & Medium \\
\hline Sampling Intensity ${ }^{2}$ & Medium & Medium & Medium & Medium & Medium \\
\hline Atrazine in catchment 39 & 1995 & 1996 & 1997 & 1998 & 1999 \\
\hline Spatial Intensity $^{1}$ & Low & Medium & Medium & Medium & Medium \\
\hline Sampling Intensity $^{2}$ & Medium & Medium & Medium & Medium & Medium \\
\hline Atrazine in catchment 50 & 1995 & 1996 & 1997 & 1998 & 1999 \\
\hline Spatial Intensity $^{1}$ & Low & Low & Low & Low & No data \\
\hline Sampling Intensity $^{2}$ & Low & Medium & Low & Low & No data \\
\hline
\end{tabular}

Notes:

1: A ratio of the number of sampling sites to catchment size: $<0.4$ low; $0.4-0.8$ medium,

$>0.8$ high.

2: A ratio of the number of samples taken in the region to number of sampling sites: $<11$ is categorised as low, 11 to 34 medium, $34-300$ high, > 300 very high. 
